\title{
REgulamentaÇão dos Planos de SAÚde E A PROTEÇÃO DO CONSUMIDOR
}

REGULATION OF PRIVATE PLANS OF HEALTH'S ASSISTANCE AND THE PROTECTION OF CONSUMERS RIGHTS

Roberto Augusto Castellanos Pfeiffer(*)

\section{RESUMO}

O artigo discorre sobre a regulamentação dos planos privados de assistência à saúde, matéria de destacada relevância, em virtude do elevado número de consumidores a eles vinculados, bem como pela singularidade do seu objeto.

O ensaio delineia o contexto normativo em que foi recepcionada a lei regulamentadora dos planos de saúde (Lei n. 9.656, de 3 de junho de 1998), destacando as normas da Constituição da República Federativa do Brasil e do Código de Defesa do Consumidor - CDC pertinentes à matéria, defendendo a necessidade de aplicação conjunta de tais normas de conteúdo geral com as regras específicas da Lei $n$. 9656/98, a fim de potencializar a defesa dos consumidores de planos de saúde.

Estabelecidas tais premissas, o artigo aborda os principais aspectos da Lei n. 9.656/98 relacionados com a proteção dos consumidores.

\section{Palavras-chave}

Direito sanitário, saúde suplementar; direito do consumidor.

\section{ABSTRACT}

The article focuses the regulation of health assistance private plans, a theme of elevated importance due not only to the large number of consumers involved, but also to the singularity of the matter.

(") Consultor Jurídico do Ministério da Justiça. Ex-assessor de Ministro do Supremo Tribunal Federal. Procurador do Estado de São Paulo. Mestre em Direito pela Universidade de São Paulo (USP). Diretor do Brasilcon e do IBAP. 
The normative context existing before the enactment of the law that regulated health plans (Law 9658, June 03/1998) is outlined, emphasis given to provisions of both the Federal Constitution and the Consumers' Code as related to the subject, supporting the need of an integrated enforcement of such general provisions together with the specific rules of Law 9658, so as to strengthen the protection of consumers' rights.

In the last part, the article analyses the main features of Law 9656 that are related to consumers' protection.

\section{Key words}

Health law; health private plans; consumers rights.

\section{INTRODUÇÃO}

Os planos e seguros privados de assistência à saúde passaram a revestir-se de especial relevância a partir da década de 80 , com o enorme crescimento da demanda por tais serviços. Segundo dados da Fundação SEADE, existem atualmente mais de $\mathbf{4 0}$ milhões de brasileiros vinculados aos planos e seguros de saúde(1).

Assim, os altíssimos custos da medicina privada e a gradativa perda de qualidade dos serviços públicos impulsionaram a expansão dos planos e seguros de assistência privada à saúde, em que firmam contratos de natureza aleatória, nos quais é pactuada a obrigação dos consumidores pagarem parcelas mensais, enquanto os fornecedores obrigam-se a custear os gastos médicos que forem necessários ao restabelecimento da saúde do consumidor, sempre que ocorrer o evento aleatório, ou seja, a necessidade de tratamento.

Diversos fatores demonstravam que o sistema demandava, efetivamente, uma regulamentação específica. Em primeiro lugar, a circunstância de a saúde ser um bem especialíssimo, que merece um tratamento diferenciado. Em segundo lugar, as enormes desigualdades entre os consumidores dos serviços privados de saúde e os seus fornecedores. Pode-se destacar

(1) Dados da Fundação Seade mostram que, de 1987 a 1994 houve, além de um sensivel crescimento do número absoluto de consumidores, uma mudança em seu pertil. Assim, embora o número de pessoas abrangidas pelo sistema privado de planos e seguros saúde tenha crescido em 12 milhões de participantes nesse período, nota-se alteração nas proporções em cada classe social: entre os individuos da classe $A$ (classe de renda) o total de abrangidos saltou de $65 \%$ para $80 \%$ entre 1990 e 1994. Já na classe D, no mesmo periodo de 1990 a 1994, o número caiu de $23,3 \%$ para $18 \%$. Houve, dessa maneira, um aumento da participação dos mais ricos e uma queda dos mais pobres. Contribuem para tal circunstância a maior contratação de planos individuais em comparação com os coletivos, bem como a crescente queda de emprego e renda da população mais pobre. 
ainda os altíssimos custos envolvidos e o enorme número de reclamações administrativas e de ação judiciais movidas pelos consumidores. Finalmente, o fato de que a impossibilidade do sistema público oferecer efetiva e adequada cobertura universal ter colaborado para a expansão dos planos de assistência privada.(2)

A promulgação do CDC permitiu uma adequada proteção dos usuários dos planos em relação a abusos praticados pelas operadoras. No entanto, mesmo assim havia expectativa geral pela edição de uma lei que tratasse especificamente o tema, a fim de positivar interpretações jurisprudenciais consolidadas, aclarar aspectos controvertidos, permitir uma ação administrativa mais contundente, bem como dispor sobre a constituição e regime das operadoras. Assim, após um amplo debate veio a ser promulgada a Lei n. 9656, de 03 de junho de 1998. ${ }^{(3)}$

Antes de analisar aspectos pontuais da referida lei, entendo importante destacar o contexto normativo dentro do qual ela se insere e com o qual deve ser aplicada de modo harmônico.

\section{DAS NORMAS CONSTITUCIONAIS DE REGÊNCIA.}

A Constituição Federal - CF reservou um capítulo exclusivo para o tratamento do tema, preocupando-se, sobretudo, com a saúde pública. Entretanto, mesmo os serviços de assistência privada à saúde devem atender a algum dos princípios constitucionais, já que são considerados também de relevância pública (art. 197, da Constituição Federal). Por sinal, os planos e seguros de saúde também ganharam a dimensão que hoje possuem em

(2) José Reinaldo de Lima Lopes ressalta com precisão que mesmo em sociedades tipicamente liberais são impostas restrições à atividade privada: "O exemplo mais claro vem hoje dos Estados Unidos, onde a inexistência de um sistema público universal exigiu que a indústria médica fosse altamente regulada. As razões dadas para isto são várias. Alega-se que não é verdade que as pessoas tratem sua saúde como o primeiro e mais valioso bem. Há estilos de vida claramente não recomendáveis (fumo, bebida, etc.) e mesmo assim as pessoas continuam fazendo estas coisas. Além dos gastos médicos há muitas outras coisas que favorecem a saúde: dietas, meio ambiente, fatores hereditários, etc. e tudo isto precisa ser levado em conta quanto se pensa na saúde pública (na harmonização dos recursos públicos e privados). Há uma parte dos gastos médicos que é puro e simples desperdício: estudos nos Estados Unidos mostram que 50 a $65 \%$ dos antibióticos são prescritos de forma inadequada e que cerca de um terço dos 75 milhões de raios-X de tórax não eram necessários (Hall \& Ellman, 1990, p. 5). Verifica-se que a característica de cobertura do sistema pode dar um incentivo à escalada de custos. Assim, no setor privado as administradoras de saúde estruturaram-se para cobrir individualmente os serviços prestados (fee-for-service) enquanto que no setor público o sistema tem sido de custo (para hospitais) ou cobrança (para médicos). Neste sistema, os fornecedores são reembolsados pelos custos incorridos no tratamento de pacientes incluidos na cobertura". (Lopes, 1999, p. 25).

(3) A lei em destaque originou-se do Projeto de Lei do Senado Federal $n$. 93, de 08 de julho de 1993. A Medida Provisória n. 1.976 e n. 2.097, vêm procedendo, desde o dia 04 de junho de 1998, alteraçōes no conteúdo da lei, o que tem gerado relativa insegurança jurídica para as partes envolvidas. 
razão de muitas pessoas não confiarem no serviço de saúde disponibilizado pelo Estado.

Assim, a disposição contida no art. 199 da CF que, em seu $\S 1^{\circ}$ estipula ser livre à iniciativa privada a assistência à saúde, que dela participar de forma complementar, deve ser interpretada sempre tendo em vista a relevância pública do serviço prestado.(4)

A corroborar tal assertiva, observa-se que a CFde 1988 dedicou especial consideração à preservação da dignidade da pessoa humana, à proteção do consumidor e aos direitos sociais. ${ }^{(5)}$

Com efeito, $\mathrm{o}$ art. $1^{2}$, III, da CF estabelece que um dos fundamentos do Estado Democrático de Direito é a dignidade da pessoa humana. E os direitos fundamentais que integram a dignidade da pessoa humana são, além dos dispostos em seu art. $5^{\circ}$, também os enumerados no art. $6^{\circ}$, ou seja, os direitos sociais, dentre os quais foi incluída, de forma expressa, a saúde. Assim, o art. 19, III, da CF estabelece que um dos fundamentos do Estado Democrático de Direito é a dignidade da pessoa humana. $E$ os direitos fundamentais que integram a dignidade da pessoa humana são, além dos dispostos em seu art. $5^{\circ}$, também os enumerados no art. $6^{\circ}$, ou seja, os direitos sociais, dentre os quais foi incluída, de forma expressa, a saúde.

Desse modo, todo contrato que contiver disposições ou cuja operadora adotar práticas que atentem contra a dignidade da pessoa humana, incidirá em afronta à CF. O titular do direito ao acesso universal da saúde deve ter a mais ampla proteção e a seu favor serem dirimidas quaisquer dúvidas. Devem, ainda, ser considerados inconstitucionais todos os atos normativos que regulem de forma contrária a estes ditames.

Por seu turno, dispõe o art. 5, XXXII da CF, que "o Estado promoverá, na forma da lei, a defesa do consumidor". Não bastasse tal disposição, esta-

(4) Como bem ressalta Sarrubo, 1999, p. 18: “(...) se a Constituição Federal facultou à iniciativa privada participar da assistência à saúde de forma complementar, concluiu-se que as prestadoras de tais serviços suprem as deficiências do Estado, mediante autorizaçāo constitucional, e suprindo tais serviços, à semelhança do que ocorre com o Estado, devem garantir o direito à saúden.

(5) A grande preocupação das Constituições atuais com os direitos sociais é bem salientada pela doutrina: "Também está em crise a concepção clássica de Constituição que restringe a sua função à limitação do poder e à garantia das liberdades políticas. O texto constitucional não pode nem deve ser considerado como simples estatuto jurídico de repartição do poder do Estado e de garantia dos direitos e liberdades. A força normativa da Constituição expande-se até o terreno da ordem econômica e social. Mesmo nos domínios em que a Constituição tradicionalmente não penetrava ou em relação aos quais costumava ser olhada apenas como "mensagem" ou "utopia", reconhecese hoje a força conformadora das normas constitucionais. Conseqüentemente, a Constituição tanto é lei fundamental dos "direitos, liberdades e garantias", como dos direitos económicos, sociais e culturais; tanto é imperativo jurídico no que respeita ao estatuto dos órgãos de soberania, como quando trata da organização econômica ou das relações sociais em geral" (Canotilho e Moreira, 1994, pp. 43-44). 
belece ainda a nossa Constituição que a ordem econômica, que tem por fim assegurar a todos existência digna, conforme os ditames da justiça social, deve observar uma série de princípios, dentre os quais o da defesa do consumidor (art. 170, V, da CF).

Nesse contexto, qualquer prerrogativa que desequilibre, contra o consumidor, a relação estabelecida com o fornecedor, é inconstitucional. Por outro lado, leis que imponham limites à atuação das empresas à livre iniciativa, fundamentadas na defesa do consumidor, são plenamente conforme com a CF. A esse respeito é importante, inclusive, mencionar o posicionamento do Supremo Tribunal Federal, que, ao julgar ação relativa a regras estatuídas em lei que impunham restrições a reajustes de mensalidades escolares, ressaltou que:

"EMENTA: - Ação direta de inconstitucionalidade. Lei n. 8.039, de 30 de maio de 1990, que dispõe sobre critérios de reajuste das mensalidades escolares e dá outras providências.

- Em face da atual Constituição, para conciliar o fundamento da livre iniciativa e do princípio da livre concorrência com os da defesa do consumidor e da redução das desigualdades sociais, em conformidade com os ditames da justiça social, pode o Estado, por via legislativa, regular a política de preços de bens e de serviços, abusivo que é o poder econômico que visa ao aumento arbitrário dos lucros.

- Não e, pois, inconstitucional a Lei n. 8.039, de 30 de maio de 1990, pelo só fato de ela dispor sobre critérios de reajuste das mensalidades das escolas particulares (...)".(6)

Finalmente, deve ser ressaltado que 0 art. 197 da CF, ao destacar 0 caráter de relevância pública das ações e serviços de saúde, determina que lei disporá sobre a sua regulamentação, fiscalização e controle.

\section{DA PRESENÇA DE RELAÇÃO DE CONSUMO E CONSEQÜENTE APLICAÇÃO DO CÓDIGO DE DEFESA DO CONSUMIDOR}

A análise da relação estabelecida entre as operadoras de planos e seguros de saúde evidencia uma modalidade especial de contrato: trata-se de

(6) STF- Tribunal Pleno - Rel. Min. Moreira Alves, DJ 30.4.93, p. 7563. Em seu voto, o relator do acórdão, ao destacar a necessidade de conciliar o fundamento da livre iniciativa com os princípios da defesa do consumidor e da redução das desigualdades sociais, destaca que: "Para se alcançar o equilíbrio da relatividade desses princípios - que, se tomados em sentido absoluto, como já salientei, são inconciliáveis - $\theta$, portanto, para se atender aos ditames da justiça social que pressupõe esse equilíbrio, é mister que se admita que a intervenção indireta do Estado na ordem econó. mica não se faça apenas a posteriori, com o estabelecimento de sanções às transgressōes já ocorridas, mas também a priori, até porque a eficácia da defesa do consumidor ficará sensivelmente reduzida pela intervenção somente a posteriori, que, às mais das vezes, impossibilita ou dificulta a recomposição do dano sofrido". 
relação de consumo, já que as operadoras e seguradoras, prestando o serviço objeto de contratação de maneira reiterada e mediante remuneração, enquadram-se perfeitamente no conceito de fornecedores, conforme dispõe o art. $3^{\circ}, \S 2^{\circ}$ do CDC.

Aliás, justamente tendo em vista a efetiva incidência de relação de consumo, 0 art. $3^{\circ}$ da Lei n. 9.656/98 determina expressamente a aplicação subsidiária do CDC.

Assim, as cláusulas que integram os contratos firmados entre as partes devem necessariamente ser interpretadas à luz dos preceitos do CDC, que trouxe um novo paradigma para a regulação das relações de consumo, que partindo da premissa do desequilíbrio intrínseco existente nas relações de consumo, estabelece uma série de normas de natureza compensatória a fim de conferir tratamento desigual a partes efetivamente desiguais e estabelecendo, assim, uma concepção social do contrato. ${ }^{(7)}$

Dentre as inúmeras regras introduzidas no ordenamento jurídico, interessa-nos, na análise da matéria, destacar as seguintes, incluídas no rol de direitos básicos do consumidor (art. 6 do CDC):

- informação adequada e clara sobre os diferentes produtos e serviços, com especificação correta de quantidade, características, composição, qualidade e preço, bem como sobre os riscos que apresentem;

- proteção contra a publicidade enganosa e abusiva, métodos comerciais coercitivos e desleais, bem como contra práticas e cláusulas abusivas ou impostas no fornecimento de produtos e serviços;

- modificação das cláusulas contratuais que estabeleçam prestações desproporcionais ou a sua revisão em razão de fatos supervenientes que as tornem excessivamente onerosas.

Um outro aspecto de suma importância é a necessidade das cláusulas serem redigidas de maneira clara. Assim, quaisquer restrições permitidas pela lei, em obediência ao princípio da boa-fé na redação do contrato, deverão estar claramente redigidas e em destaque, sob pena de não o estando, deixarem de vincular o consumidor, como se infere da leitura dos arts. 46 e $54, \S 4^{\circ}$, do CDC e do art. 16 da Lei n. 9.656/98. ${ }^{(8)}$

(7) "A nova concepção de contrato é uma concepção social deste instrumento jurídico, para a qual não só o momento da manifestação da vontade (consenso) importa, mas onde também e principalmente os efeitos do contrato na sociedade serão levados em conta (...). À procura do equilíbrio contratual, na sociedade de consumo, o direito destacará o papel da lei como limitadora e verdadeira legitimadora da autonomia da vontade. A lei passará a proteger determinados interesses sociais". (Marques, 1994, p. 74)

(8) A este respeito, cumpre transcrever trecho do seguinte acórdão: "A cláusula que exclui o direito à internação hospitalar, em letras bem pequenas evidencia que a contratada não cumpriu com a 
Inclusive, o CDC estabelece princípios que devem reger a interpretação de qualquer nova regra sobre relações de consumo. Portanto, entendemos plenamente possível uma harmonização das disposições da lei regulamentadora dos planos e seguros de saúde com as regras mais gerais do CDC. ${ }^{(9)}$

Importante, ainda, recordar que a relação entre as operadoras e os consumidores de planos de saúde estabelece-se por intermédio de um contrato de adesão, o que, por si só, impõe a plena aplicação das disposições do CDC. ${ }^{(10)}$

\section{DOS PRINCIPAIS ASPECTOS DA REGULAMENTAÇÃO EFETIVADA PELA LEI N. 9.656/98}

Estabelecido esse quadro, que delineia, de forma sintética, o contexto normativo no qual foi recepcionada a Lei n. 9.656/98, cumpre destacar os principais aspectos por ela tratados. Como os temas são variados e de gran-

obrigação legal de dar destaque às limitações do direito do consumidor (art. 46 do CDC). De se concluir, portanto, que o caso sub judice não pode ser solucionado pura e simplesmente com a invocação do vetusto princípio do pacta sunt servanda, já que, tratando de relacionamento contratual de adesão, formado entre consumidor hipossuficiente e iletrado a empresa de assistência médico-hospitalar dirigida por médico, incide com toda sua plenitude o Código de Defesa do Consumidor, sendo de rigor a aplicação dos arts. 46 e 47 do Codex. A conclusão, portanto, é a da procedência da ação para o fim de reconhecer a responsabilidade da contratada pelo pagamento das despesas médico-hospitalares decorrentes da internação do contratante". (TJSP - Ap. n. 240.4292/6 - 16 C. - Rel. Des. Pereira Calças - j. em 25.10.94 - in RT 719/129).

(9) "Se a lei nova quisesse revogar algum direito do consumidor assegurado pelo código de defesa do consumidor teria que fazê-lo expressamente ou elaborando normas expressamente em conflito com as do Código de Defesa do Consumidor, o que incorre, ao contrário, reafirma aplicação conjunta de ambas as leis. Para os contratos anteriores, pois, vige apenas o Código de Defesa do Consumidor, mas sob a luz do que agora foi positivado como legalmente abusivo (limitações, cláusulas de exclusão muito amplas, como a de doenças preexistentes, aumentos desmesurados e não-informados face à idade etc.), assegurando assim novo brilho aos direitos dos consumidores já assegurados de forma genérica no Código. É como se o aplicador do Código de Defesa do Consumidor estivesse fazendo uma interpretação teleológica (logo, atual) do fim do texto então existente, mas esta interpretação, como todas as outras, deve ser pró-consumidor (art. 47 do CDC), incorporando apenas o que vier a favorecê-lo e não o que vier a reduzir, limitar ou violar seus direitos assegurados pelo Código de Defesa do Consumidor e pela jurisprudência anteriormente estabelecida." (Marques, 1999, pp. 118-9).

(10) "Sendo assim, estamos diante de contratos de massa, nos quais destacam-se principalmente as seguintes características [Nelson Nery Júnior, Código Brasileiro de Defesa do Consumidor, $5^{a}$ ed., São Paulo, Forense Universitária, 1998, p. 361]: a) predisposição unilateral, pois é o prestador do serviço que estabelece os termos do ajuste, independentemente da participação do consumidor; b) generalidade, porque não se encontra nesse tipo de contrato especificações relativas para cada consumidor contratante; $c$ ) inalterabilidade, uma vez que discordando de alguma das cláusulas não tem força o contratante para modificá-la ou retirá-la do contrato e c) adesão, pois o contratante deve se vincular expressamente aos termos do contrato elaborado de forma unilateral pelo prestador de serviços". 
de complexidade, procurarei apenas centrar-me naqueles que dizem respeito aos direitos dos consumidores dos planos de saúde.

\section{IV.1. Espécies de planos de saúde}

Inicialmente, cabe ressaltar que a Lei n. 9.656/98, em sua versão inicial, estabelecia que seriam submetidas às suas disposições tanto as pessoas jurídicas de direito privado que operassem planos de assistência privada à saúde como aquelas que ofertassem seguros de assistência privada à saúde.

Importante alteração foi introduzida pela MP n. 1.976-22, de 11 de janeiro de 2000, que alterando 0 art. $1^{\circ}$ da referida lei, estabeleceu que somente as empresas operadoras de planos de saúde submeter-se-íam às suas disposições.

Com tal modificação, as seguradoras não mais poderiam prestar serviço de assistência privada à saúde nos moldes regrados na Lei n. 9.656/98. Poderiam, apenas, prestar a atividade de seguro-saúde na forma estabelecida no Decreto-lei n. 73/66: atividade financeira típica de seguradoras, em que é estabelecida a obrigação da empresa pagar diretamente o valor ao prestador do serviço livremente escolhido pelo segurado, não podendo prestar o serviço de assistência médica, seja diretamente ou por intermédio de terceiros.

No entanto, a Medida Provisória n. 2.122, veio a introduzir nova modificação em tal quadro, ao estabelecer, em seu art. $1^{\circ}$ que "as sociedades seguradoras poderão operar o seguro enquadrado no art. $1^{2}$, inciso $l$ e $\S 1^{\circ}$, da Lei n. 9.656, de 3 de junho de 1998, desde que estejam constituídas como seguradoras especializadas nesse seguro, devendo seu estatuto social vedar a atuação em quaisquer outros ramos ou modalidades."

Assim, as seguradoras voltaram a poder operar seguros com as características previstas na Lei $n$. 9.656, sendo-Ihes aplicáveis todas as regras de tal lei, em especial aquelas relacionadas com a proteção dos consumidores. Tanto isso é verdade que estabelece 0 art. $2^{\circ}$ da referida Medida Provisória:

"Para efeito da Lei n. 9.656, de 1998, e da Lei n. 9.961, de 2000, enquadra-se o seguro saúde como plano privado de assistência à saúde e a sociedade seguradora especializada em saúde como operadora de plano de assistência à saúde."

Procedido este esclarecimento, passo à análise das principais regras quanto às espécies de planos que podem ser ofertados. 


\section{IV.1.1. Planos abertos e planos fechados}

Conforme estipula 0 art. $1^{9}$ da Resolução n. 5 do CONSU, de 3 de novembro de 1998, os planos privados fechados de assistência à saúde são autogeridos por empresa, grupo de empresas, associações, sindicatos e entidades de classes profissionais, e destinam-se exclusivamente a empregados ativos, aposentados, pensionistas e ex-empregados, participantes de associações, sindicatos ou entidades de classes profissionais, bem como seus respectivos parentes, consangüíneos e afins até o terceiro grau.

Já os planos privados abertos, de assistência à saúde, podem ser ofertados por pessoas jurídicas, que podem adotar qualquer forma jurídica de constituição.

\section{IV.1.2. Plano-referência e planos segmentados}

O art. 10 da Lei n. 9.656/98 obriga as operadoras de plano privado aberto a ofertar plano ou seguro-referência, que assegure atendimento ambulatorial, hospitalar, odontológico e obstétrico.

Nesse plano ou seguro-referência há cobertura em relação a todas as doenças relacionadas na Classificação Estatística Internacional de Doenças e Problemas Relacionados com a Saúde, da Organização Mundial de Saúde - OMS (inclusive transtornos psiquiátricos), com exceção de alguns dos procedimentos relacionados no art. 10.(11)

Permitiu a lei que as empresas oferecessem também planos segmentados, que abarcassem apenas um dos segmentos abrangidos pelo planoreferência.

O plano ambulatorial deve abarcar: a) cobertura de consultas médicas, em número ilimitado; b) cobertura de serviços de apoio diagnóstico, tratamento e demais procedimentos ambulatoriais.

Por seu turno, o plano hospitalar deve incluir: a) cobertura de internações hospitalares em centro de terapia intensiva, vedada a limitação de prazo a critério de médico assistente; b) despesas referentes a honorários médicos, serviços gerais de enfermagem e alimentação; c) cobertura de exames complementares indispensáveis para o controle da evolução da doença e elucidação diagnóstica, fornecimento de medicamentos, anestésicos, oxigênio, transfusões e sessões de quimioterapia e radioterapia, conforme prescrição do médico assistente, realizados ou ministrados durante o período de

(11) A saber: tratamento clínico ou cirúrgico experimental; procedimentos clínicos ou cirúrgicos estéticos; tratamento de rejuvenescimento ou de emagrecimento com finalidade estética; fornecimento de medicamentos importados; fornecimento de medicamentos para tratamento domiciliar; fornecimento de próteses, órteses e seus acessórios não ligados ao ato cirúrgico; tratamentos ilicitos ou antiéticos. 
internação hospitalar; d) cobertura de taxa de sala de cirurgia, incluindo despesas correlatas, dentro dos limites de abrangência geográfica previstos no contrato e despesas de acompanhante, no caso de pacientes menores de dezoito anos.

O Plano odontológico deve cobrir consultas, exames auxiliares, procedimentos preventivos de dentística e endodontia, cirurgias orais menores, isto é, as realizadas em ambulatório e sem anestesia geral (art. 12, IV, $a, b$ e $c$ ).

Já o plano hospitalar com atendimento obstétrico deve garantir cobertura assistencial ao recém-nascido durante os primeiros trinta dias após o parto.

A lei assegura também, inscrição do recém-nascido no plano ou seguro como dependente, dispensado o comprimento dos períodos de carência, desde que a inscrição ocorra no prazo máximo de trinta dias do nascimento (art. 12, III, a e b). Não há, no caso, possibilidade de recusa de inclusão do recém-nascido no plano, seja qual for o motivo.

Interpretamos que a cobertura assistencial estende-se ao recém-nascido, filho natural, adotivo, ou à criança sobre quem o beneficiário (titular ou dependente) detenha a guarda judicial. Ademais, entendo que a cobertura assistencial estende-se ao recém-nascido durante os primeiros trinta dias após o parto ou enquanto durar o tratamento, se iniciado durante os primeiros trinta dias. Com efeito, pode ocorrer que o recém-nascido permaneça mais de trinta dias em tratamento, sendo razoável que todas as despesas sejam custeadas pela operadora, uma vez que a Lei, nos arts. 10 e 12, é precisa quanto à impossibilidade de limitação de internação, pois visa a efetiva recuperação da saúde do contratante.

\section{IV.2. Extensão da cobertura}

\section{IV.2.1. Aplicação a todas as doenças sem limites de procedimento}

A Lei n. 9.656/98 foi clara ao determinar a necessidade de amplíssima cobertura a todas as espécies de doenças e à impossibilidade de limitação de dias de internação, podendo apenas ser excluídos os procedimentos relacionados no art. 10.

Importante ressaltar que $\circ$ art. $12, \S 1^{\circ}$, II, da Lei $n$. 9.656/98 impunha que os planos e seguros segmentados em qualquer de suas modalidades, abarcassem o tratamento das doenças constantes na Classificação Internacional da OMS.

Infelizmente, a alteração que vem sendo procedida à redação original do artigo pela Medida Provisória n. 1.908 não alude expressamente a tal 
amplitude de cobertura. Entendo, no entanto, que prevalece a necessária cobertura a todas as doenças classificadas pela OMS, em virtude da prescrição constante do art. 12 da referida lei que, ao facultar a contratação e a vigência de planos ou seguros privados de assistência à saúde, nas segmentações previstas nos seus incisos I a IV, estabelece que devem ser respeitadas as respectivas amplitudes de cobertura definidas no plano ou seguro-referência de que trata 0 art. 10.(12)

Assim, embora possa ser específico na espécie de atendimento, o plano segmentado deve oferecer a mesma extensão de cobertura oferecida ao respectivo segmento pelo plano ou seguro referência. Conseqüentemente, na segmentação de atendimento ambulatorial e hospitalar, todas as doenças catalogadas pela OMS, necessariamente estarão compreendidas. Já nos planos exclusivamente odontológicos ou obstétricos, deverão ser cobertas todas as doenças relacionadas com essas duas áreas.

Importante, inclusive, ressaltar que as disposições do CDC já eram suficientes para considerar nulas cláusulas restritivas da cobertura de algumas doenças.

Com efeito, estabelecem os artigos $18, \S 6^{\circ}$, III e $20, \S 2^{\circ}$, do CDC, a necessidade da adequação dos produtos e serviços à expectativa legítima do consumidor. É evidente que, ao contratar um plano ou seguro de assistência privada à saúde, o consumidor tem a legítima expectativa de que, caso fique doente, a empresa contratada arcará com os custos necessários ao restabelecimento de sua saúde. As cláusulas restritivas atentam contra a expectativa legítima do consumidor de integral assistência para o restabelecimento da Saúde. ${ }^{(13)}$

Ademais, há desvirtuamento da natureza do contrato quando uma só das partes limita o risco, que é assumido integralmente pela outra. Enquanto os contratantes assumem integralmente o risco de eventualmente pagarem a vida inteira o plano e jamais se beneficiarem dele, a operadora apenas assume o risco de arcar com os custos de tratamento de determinadas doenças, normalmente da mais simples (e, conseqüentemente, mais barata) solução, atentando contra a natureza aleatória do contrato, infringindo, assim, as normas do inciso I, IV e $\S 1^{\circ}$ do art. 51 do CDC. ${ }^{(14)}$

(12) Mesma opinião de Pasqualoto, 1999, pp. 118-9.

(13) Neste contexto, merece destaque o seguinte acórdão: "Não infringe aos artigos 1.432 e 1.460 do CC a interpretação de que a cláusula, excluindo "casos crônicos", dentre os quais se situa a diabetes mellius, não se aplica ao segurado em idade avançada. Interpreta-se o contrato de acordo com a sua finalidade econômica e ninguém contrata tal tipo de seguro senão para ver cobertos, oportunamente, os achaques da idaden. (TJRS - Ap. 695.094.482 - 5 C. - Rel. Des. Araken de Assis- j. em 24.10.96).

(14) Ver, a propósito: TJSP - A.C. 188.788-2 - $12^{\circ}$ Câmara Cível - Rel. Des. ÉRIX FERREIRA - j. em 28/04/92 - in RJTJESP $137 / 95$. 


\section{IV.2.2. As doenças preexistentes}

Uma das maiores fontes de conflito entre operadoras de planos de saúde e consumidores diz respeito à negativa de cobertura de doenças que as operadoras alegam que preexistiam à data da contratação, matéria que veio a ser objeto de expresso tratamento na lei regulamentadora. Assim, estabelece o art. 11 da Lei n. 9.656 que "é vedada a exclusão de cobertura às doenças e lesões preexistentes à data de contratação dos planos ou seguros de assistência privada à saúde após vinte e quatro meses de vigência do instrumento contratual, cabendo à respectiva operadora o ônus da prova e da demonstração do conhecimento prévio do consumidor"(15).

A regra estatuída pela lei regulamentadora dos planos de assistência privada à saúde é bastante clara: decorridos vinte e quatro meses de vigência da relação contratual, a fornecedora deverá, obrigatoriamente, arcar com as despesas do tratamento da doença sofrida pelo seu consumidor, não podendo, de maneira alguma, alegar que a doença é preexistente, pouco importando, inclusive, se o consumidor tinha ou não conhecimento prévio da existência da doença.

Por outro lado, caso o consumidor, no momento da contratação, faça menção à doença, poderá optar entre:

a) Aderir ao plano com restrição da cobertura da doença mencionada (o que a Resolução n. 02 do CONSU denomina de cobertura parcial temporária). Após o transcurso dos dois anos a cobertura será ampla, incluindo a doença mencionada. Entendemos, inclusive, que o mais justo será a cobrança de um menor preço durante os dois primeiros anos, pois há diminuição do risco da empresa(16).

b) Poderá, ainda, optar por uma majoração dos custos do plano, em que esteja incluida a cobertura para os males por ele declinados (o que a Resolução 2 do CONSU denomina de agravo do contrato). Neste caso, entendemos que a majoração somente pode valer para os dois primeiros anos. Depois, o preço deve voltar ao padrão comum, já que, depois de decorrido o

(15) A Resolução n. 02 do CONSU define que doenças preexistentes são aquelas que o consumidor sabia ser portador ou sofredor, à época da contratação de planos ou seguros privados de assistência à saúde (art. 19).

(16) Estabelece a Resolução 2 do CONSU, ainda, que, caso o consumidor opte pela cobertura parcial provisória: a) os atendimentos caracterizados como urgência e emergência relacionadas à doença ou lesão preexistente terão cobertura igual áquela assegurada na segmentação ambulatorial, independente do contrato firmado (art. $5^{2}, \S 1^{9}$ ); b) findo o prazo da cobertura parcial temporária, que pode corresponder a, no máximo, 24 (vinte e quatro) meses, a cobertura passará a ser integral, de acordo com a segmentação contratada, sem que possa ser imposto qualquer agravo ao contratante $\left(5^{\circ}, \S 2^{9}\right)$. 
biênio, a operadora ou seguradora, de qualquer modo, teria que arcar com os custos de tratamento de qualquer doença, mesmo que preexistente.

Nessa hipótese, a operadora deve oferecer proposta esclarecendo a diferença de valores envolvidos em comparação com os demais planos da mesma segmentação, devendo, quando solicitada pelo Ministério da Saúde, comprovar os valores resultantes.

\section{2.3. Ônus da prova da preexistência}

O art. 11 da Lei n. 9.656/98 deixou claro que será da operadora o ônus de demonstrar que é preexistente a doença para cujo tratamento nega cobertura antes de transcorridos dois anos da contratação. ${ }^{(17)}$

Entendo, ainda, que ao fornecedor não bastará alegar a preexistência da doença, devendo, ainda, provar a má-fé do consumidor em ocultá-la.

Com efeito, pode acontecer de o consumidor, em violação clara ao princípio da boa-fé, ocultar a existência de uma doença, algo que pode ser facilmente provado por indícios como a existência de tratamentos anteriores ou a clara manifestação de sintomas. Nessa hipótese, não poderá ter cobertos os custos do tratamento da doença.

No entanto, pode ocorrer de o consumidor não ter conhecimento da existência da doença, já que até então nenhum sintoma havia se manifestado. Nesse caso, não é justo que a operadora negue a cobertura. Cabe ao fornecedor, a partir das informações obtidas na entrevista qualificada que fará com o consumidor, caso desconfie de indícios de preexistência de doença, exigir que ele se submeta a alguns testes para verificar se possui alguma espécie de doença que pode manifestar-se no prazo de dois anos. Se não o fizer e não demonstrar que o consumidor omitiu propositadamente a doença ou informações relevantes, não poderá deixar de cobrir os custos do tratamento. Cumpre, a propósito, destacar o seguinte acórdão do Superior Tribunal de Justiça:

"A empresa que explora planos de saúde e admite associado sem prévio exame de suas condições de saúde, e passa a receber as suas contribuições, não pode, ao ser chamado ao pagamento de sua contraprestação, recusar a assistência devida sob a alegação de que o segurado deixara de prestar informações sobre o seu estado de saúde".

(17) Tal dispositivo encontra eco no CDC, especialmente em seu art. $6^{\circ}$, VIII (que trata da inversão do ónus da prova a favor do consumidor no processo civil) e em seu art. 47, que estabelece a regra hermenêutica de que as cláusulas contratuais sejam interpretadas da maneira mais favorável ao consumidor. 
O segurado é um leigo, que quase sempre desconhece o real significado dos termos, cláusulas e condições constantes dos formulários que Ihe são apresentados. Para reconhecer a sua malícia, seria indispensável a prova de que, 1. realmente, fora ele informado e esclarecido de todo o conteúdo do contrato de adesão, e, ainda, 2. estivesse ciente das características de sua eventual doença, classificação e efeitos.

A exigência de um comportamento de acordo com a boa-fé recai também sobre a empresa que presta a assistência, pois ela tem, mais do que ninguém, condições de conhecer as peculiaridades, as características, a álea do campo de sua atividade empresarial, destinada ao lucro, para o que corre um risco que deve ser calculado antes de se lançar no empreendimento.

O que não se lhe pode permitir é que atue indiscriminadamente, quando se trata de receber as prestações, e depois passe a exigir estrito cumprimento do contrato para afastar a sua obrigação de dar cobertura às despesas". ${ }^{(18)}$

Cumpre, inclusive, ressaltar que tal conclusão é justificada não somente pela aplicação do sistema do CDC, mas até mesmo pela correta interpretação do Código Civil. Tal conclusão impõe-se a partir da análise da regra do art. 1.444 do $\mathrm{CC}$, que determina o dever de prestação de informações verdadeiras. A melhor interpretação é a de que o segurador, para exonerar-se de pagamento do sinistro, deverá provar não somente a incorreção da informação prestada, mas também o conhecimento do segurado sobre estar errônea ou omissa a sua declaração. É essa a posição jurisprudencial, como exemplifica o seguinte acórdão do Superior tribunal de Justiça:

"O conceito de informação verdadeira e não omissão difere do leigo para o técnico. De toda a sorte, a seguradora obriga-se em questionar as informações. O pretenso segurado pratica um ato, dá informações, e a seguradora os examina e os confronta. A conduta do segurado é omissiva, só informa e autoriza, a da seguradora é comissiva, deve verificar as informações, está autorizada para tanto. A responsabilidade da exatidão das informações é repartida e implica, no contexto da ética médica, conhecimentos técnicos e psicologicamente adequados.

Não se pode aceitar que uma seguradora só busque as informações para a verificação das veracidades, após a consumação do fato determinativo do pagamento do prêmio, apoiada no texto que lhe faculta a

(18) STJ - Resp n. 86.095-SP - 4" T. - Rel. Min. Ruy Rosado de Aguiar - j. em 22.4.96 - in Direito do Consumidorn. 20, p. 151. 
retenção, sem ônus, do prêmio, ser ter anteriormente elaborado diligências para a verificação. Seria uma imoralidade".(19)

Finalmente, necessário destacar importante modificação inserida pela Medida Provisória n. 1.685/98 no art. 11, parágrafo único, da Lei n. 9.656/ 98 , estabelecendo ser "vedada a suspensão da assistência à saúde do consumidor, titular ou dependente, até a prova de que trata o caput, na forma da regulamentação a ser editada pelo CONSU". Por seu turno, a Resolução n. 2 do CONSU, em seu art. $7^{\circ}, \S 7^{\circ}$, dispõe que "não será permitida, sob qualquer alegação, a suspensão do contrato até o resultado do julgamento (da alegação de conhecimento do consumidor sobre a preexistência) da doença pelo Ministério da Saúde".

\section{IV.2.3. Regramento das carências}

As carências são cláusulas que operam uma limitação na eficácia do contrato: para determinadas doenças ou espécie de tratamentos, a responsabilidade da contratada somente irá ter o seu início a partir do transcurso de um lapso temporal.

Tais cláusulas estão intimamente relacionadas com o princípio da boafé e da própria viabilidade do contrato: evitam que o consumidor venha a aderir ao contrato apenas para, imediatamente, poder utilizar-se da prestação (ou reembolso) de um serviço mais complexo, permitindo, ainda, o recebimento de um numerário mínimo do consumidor ingressante, para a capitalização do fundo mútuo utilizado para a cobertura de todos os eventos.

Entretanto, é dentro desta finalidade restrita que devem ser interpretadas as cláusulas de carência. Atento a isso, o legislador incluiu disposições específicas na lei regulamentadora, limitando o prazo máximo que pode ser estabelecido para as carências. Estabelece, assim, o art. 12, V, da Lei n. 9.656: "a) prazo máximo de trezentos dias para partos a termo; b) prazo máximo de cento e oitenta dias para os demais casos; c) prazo máximo de vinte e quatro horas para a cobertura dos casos de urgência e emergência".

Portanto, qualquer cláusula que estipule período de carência superior à expressamente permitida pela lei será tida como nula de pleno direito, não

(19) STJ - A.I. n. 13.525 - 4 T - Rel. Min. Sálvio de Figueiredo - D.J.U. de 22.8.91, p. 11.591. Posicionamento semelhante encontra-se no seguinte acórdão da $3^{2}$ Turma do STJ: "Para que incida o disposto no artigo 1.444 do Código Civil, necessário que o segurado tenha feito declaraçōes inverídicas quando poderia fazê-las verdadeiras e completas. $E$ isso não se verifica se não tiver ciência do seu real estado de saúde." (STJ- Ag. Reg. n. 4.559-GO - 3" T. - Rel. Min. Eduardo Ribeiro - j. em 24.09.90 - in RJ 163, p. 39). Ver, também, os seguintes acórdãos: TJRS - Ap. n. 595.043 .845 - 39 CC - Rel. Des. Araken de Assis - j. em 20.04 .95 e . TAPR - Ap. n. 37.256-9 - Rel. Juiz Cordeiro Cleve. 
vinculando as partes contratantes, naquilo que superar o prazo máximo permitido em lei.

Ademais, cláusula que estabelecer período de carência excessivo, desproporcional à doença sobre a qual incide, contrariando a natureza do contrato e impondo ao consumidor exagerada desvantagem, deve ser tida como nula de pleno direito, aplicando-se as normas do inciso IV e $\S 1^{\circ}$, I, II e III do art. 51 do CDC, como aliás, tem entendido a nossa melhor jurisprudência. ${ }^{(20)}$

Aplica-se ainda, a regra estatuída no art. $54, \S 4^{\circ}$ do CDC e no art. 16 , III, da Lei n. 9.656/98, ficando assim, condicionada a validade das cláusulas que versam sobre a carência à sua redação com destaque e clareza, já que elas implicam limitação ao direito do consumidor, ao subordinarem a eficácia do contrato em relação a determinados eventos, ao transcurso de um lapso temporal.

Por outro lado, observa-se com freqüência fornecedores veicularem ofertas em que anunciam a "compra" de carências de consumidores de outros planos ou seguros (ou seja, que o tempo já transcorrido desde a assinatura do outro contrato será computado para efeito de superação do período de carência) ou a própria isenção completa de qualquer periodo de carência. Nestas hipóteses, caso os fornecedores incluam no contrato cláusulas de carência, não estarão desobrigados de arcar com os custos do serviço médico. Aplica-se, em tal caso, o princípio da vinculação da oferta (art. 30 do CDC). Assim, neste caso, como dispõe o art. 35 do CDC, poderá o consumidor, à sua livre escolha, optar entre: "I) exigir o cumprimento forçado da obrigação, nos termos da oferta, apresentação ou publicidade; II) aceitar outro produto ou prestação de serviço equivalente; III) rescindir o contrato, com direito à restituição de quantia eventualmente antecipada, monetariamente atualizada, e a perdas e danos".(21)

Entendemos, ainda, que jamais o atraso no pagamento pode ser usado como causa permissiva de recontagem de carências.

Com efeito, a possibilidade de recontagem da carência desequilibra a relação contratual, impondo desvantagem excessiva para o consumidor, e contraria a própria bilateralidade que é da essência dessa espécie de contrato: a um adimplemento defeituoso por parte do consumidor se contrapõe a

(20) A este respeito merece destaque o acórdão do Tribunal de Justiça de São Paulo: "ContratoCláusula - Seguro saúde - Carência - Período muito extenso - Ocorrência - Desvantagem exagerada e onerosidade para o consumidor - Art. 51, IV e $\$ 1^{2}$, III do Código de Defesa do Consumidor decisão mantida - Recurso não provido (TJSP - Ap. 242.065-2 - 10 C - Rel. Des. Borelli Machado j. em 10.11.94).

(21) Essa mesma interpretação pode ser aplicada à qualquer outra espécie de oferta, como por exemplo, a de planos e seguros que, eventualmente, veiculem cobertura irrestrita a doenças preexistentes. 
possibilidade de um inadimplemento absoluto por parte do fornecedor (que não precisa cobrir os eventos atingidos pelo novo prazo de carência). ${ }^{(22)}$

Ademais, normalmente os contratos prevêem, como sanção para o atraso no pagamento, a imposição de multa moratória, correção monetária e juros de mora. Em tais casos, as cláusulas de imposição de novos prazos de carência constituem verdadeiro bis in idem, o qual é inteiramente vedado pelo nosso ordenamento jurídico. ${ }^{(23)}$

Sensivel à esta realidade, o legislador estabeleceu, de forma absolutamente clara, no art. 13, parágrafo único da Lei n. 9.656/98, ser vedada: "I - a recontagem de carências; II - a suspensão do contrato e a denúncia unilateral, salvo por fraude ou não pagamento da mensalidade por período superior a sessenta dias, consecutivos ou não, nos últimos doze meses de vigência do contrato, desde que o consumidor seja comprovadamente notificado até o qüinquagésimo dia de inadimplência".

Ademais, o referido diploma legal, em seu art. 16, estabelece que, dentre as cláusulas contratuais devem constar dispositivos que indiquem com clareza, "os bônus, descontos ou os agravamentos da contraprestação pecuniária", o que nos leva a concluir que somente poderá haver sanções pecuniárias para o adimplemento defeituoso.

Assim, a lei cristalizou a interpretação que a jurisprudência já vinha conferindo à matéria, deixando absolutamente clara a nulidade de cláusula, impondo recontagem de carência ou suspendendo a eficácia do contrato em virtude de atraso no pagamento, sendo a denúncia do contrato permitida apenas após o escoamento de prazo superior a sessenta dias de inadimplemento absoluto. Como a aplicação das regras do CDC e do próprio Código Civil induziam à mesma conseqüência, concluímos que a nulidade de tais

(22) Decisão exemplar do Tribunal de Justiça do Rio Grande do Sul destaca que: "A bilateralidade impede que ao simples adimplemento ruim (defeituoso) da obrigação do segurado se oponha 0 descumprimento da obrigação essencial da seguradora", realçando-se que "o recebimento do prêmio em parcelas de amortização monetariamente corrigidas, sem ressalvas, torna insignificante 0 prejuizo resultante do atraso no seu pagamento. Abusividade da cláusula contratual que institui carência de 60 dias na cobertura quando de atraso superior a 30 dias no pagamento do prêmio, em tais condições" (TJRS - 2" CC - Ap. n. 592010771 - Rel. Des. Ivo Gabriel da Cunha - j. em 25.03.92).

(23) Acórdão do Tribunal de Justiça de São Paulo destaca que "constituindo a emenda ou purga da mora medida fundada na eqüidade que recompõe o contrato, restituindo-o à normalidade, é incompatível com a eqüidade que a informa a estipulação que não restitui o contrato à normalidade, mas o conduz à situação de desequilibrio entre os direitos e obrigações dos contratantes, pois enquanto ficam restabelecidas todas as obrigaçōes do consumidor, remanescem suspensos os seus direitos com a reabertura do prazo de carência, destacando que "ao invés de recolocar o contrato em situação normal, restabelecidos os primitivos direitos e obrigações de ambas as partes, a cláusula em questão (cláusula de carência), ferindo a eqüidade, cria uma situação desfavorável ao consumidor, reabrindo um prazo de carência no qual o consumidor só tem obrigações e o fornecedor só tem direitos. $E$ isso não obstante o atraso no pagamento tenha sido compensado com a correção monetária do valor devido". (TJSP - Ap. n. 235.857-2/3 - Rel. Des. Aldo Magalhães -j. em 25.08.94). 
cláusulas ocorre tanto em relação aos contratos elaborados antes como depois da vigência da nova lei regulamentadora. ${ }^{(24)}$

Finalmente, resta acrescentar que o art. da Resolução n. 14 do CONSU proíbe o estabelecimento de carências nos planos e seguros coletivos empresariais com número superior a cinqüenta participantes.

\section{IV.4. Acesso Universal e manutenção de empregados e aposentados}

A Lei n. 9.656/99 assegura a manutenção, a título individual, ainda que por tempo limitado, do consumidor egresso de plano ou seguro coletivo, em razão de rompimento do vínculo empregatício sem justa causa (art. $30, \S 1 \%$.

Assim, nessa hipótese, a rescisão do contrato de trabalho não extingue automaticamente o vínculo com o plano ou seguro privado de assistência à saúde, que perdurará por um terço do tempo de duração do contrato de trabalho. As mensalidades passam a ser pagas integralmente pelo consumidor individual, inclusive a parcela que anteriormente era de responsabilidade do empregador.

$\mathrm{O}$ art. 31 da Lei n. 9.656/98 assegura àqueles que se aposentarem, a sua permanência no plano ou seguro coletivo decorrente de vínculo empregatício, desde que tenham dez anos de contribuição, assumindo, porém, o pagamento integral da mensalidade. Se o periodo de contribuição para o plano for inferior a dez anos, a permanência no plano ou seguro será igual aos anos de contribuição.

\section{IV.5. Normas relativas aos prestadores de serviços}

\section{IV.5.1. Regras relativas ao credenciamento}

O art. 17 da Lei n. 9.656/98 determina que a inclusão de entidades hospitalares como credenciadas, contratadas ou referenciadas dos planos e seguros implica compromisso para com os consumidores quanto à sua manutenção ao longo da vigência dos contratos. Trata-se de regra destinada a coibir a prática de que, atingido um número satisfatório de aderentes, a operadora efetive o descredenciamento dos prestadores de serviço mais renomados, ocasionando queda de qualidade dos serviços prestados.

(24) Corrobora tal assertiva recente sentença que julgou procedente pedidos de declaração de nulidade de cláusulas de recontagem de carências e suspensão de coberturas em virtude de atraso no pagamento inseridas em contrato padrão da empresa que estabeleciam deduzidos em ação civil pública movida pelo Ministério Público do Estado de São Paulo. Verificar, a propósito, Revista de Direito do Consumidor, São Paulo, v. 28, set./dez. 1998, pp. 247-255 e pp. 219-223. 
O texto original do art. 17 da Lei n. $9.656 / 98$ mencionava outros estabelecimentos, a saber: casas de saúde, clínicas, laboratórios ou entidades correlatas. A Medida Provisória n. 2.097, em suas diversas reedições, retirou a menção a tais estabelecimentos, o que é lamentável, já que um dos fatores que levam as pessoas a contratar um determinado plano é justamente a publicidade da rede credenciada ${ }^{(25)}$.

Com efeito, é abusiva a prática das operadoras de, após firmado o contrato, surpreender o consumidor com a notícia de que aquele prestador fora excluído da rede, ou, o que é pior, durante o curso do tratamento, impedir o consumidor de ser atendido, sob o argumento de que houve descredenciamento do fornecedor. Trata-se de conduta que infringe $O C D C$, que veda alterações unilaterais e a publicidade enganosa, dispõe que a oferta vincula o fornecedor e impede a modificação na qualidade do contrato.

A Lei n. 9.656/98 fez constar expressamente em seu texto critérios que regulam a hipótese de descredenciamento, de modo que nos contratos firmados a partir de 04 de janeiro de 1999 ou nos contratos antigos que tenham sofrido a adaptação facultada por lei, somente poderá ocorrer descredenciamento mediante comunicação prévia - com 30 dias de antecedência - aos consumidores e ao Ministério da Saúde.

Trata-se de norma de alcance restrito, pois garante apenas a regulamentação do descredenciamento, o direito à informação do usuário e seu acompanhamento sobre a qualidade dos prestadores de serviço oferecidos pela empresa. Maior efetividade possui a exigência de substituição do prestador por outro equivalente, sendo que, na hipótese de o consumidor já estar internado em hospital que foi descredenciado, é garantida a manutenção dos mesmos prestadores até a alta hospitalar.

Nas hipóteses em que o descredenciamento for ocasionado em virtude de fraude ou infração das normas sanitárias e fiscais em vigor, não há obrigatoriedade de informação prévia, persistindo, porém, a necessidade de substituição por prestador de serviço de mesmo nível ou equivalente. Se o consumidor estiver internado durante o descredenciamento, a empresa torna-se responsável pela transferência imediata para outro estabelecimento equivalente, sem qualquer ônus para o consumidor.

(25) É expressivo o seguinte trecho de acórdão do Tribunal de Justiça de São Paulo: "Tenho chamado a atenção, quer na minha judicatura, quer no meu magistério, para esse fenómeno observável facilmente, das entidades de prestação de serviços médicos que, depois de conquistar o público com a oferta de atendimento completo e a encantadora perspectiva de uma vida despreocupada quanto a essa parte, tudo fazem para esquivar-se ao seu compromisso, até nos mais miúdos pormenores; e há aquelas que mantêm um esquema advocatício especial para resistir sempre e em tudo às exigências de cumprimento da obrigação assumida. Lastimável! Mas aos juizes cumpre não se deixarem seduzir pelos meneios da retórica insinuante que esses esquemas já têm preparados" (EI 106.119-1, Rel. Dês. Walter Moraes, RJTJESP- LEX, n. 125, p. 391). 
Aplicam-se, ainda, as regras do CDC, que, como já destacado, veda alterações unilaterais e a descaracterização da natureza do contrato. Assim, sempre que os descredenciamentos alterarem o contrato, configurarão práticas abusivas, podendo gerar sanções, inclusive de nulidade.

\section{IV.5.2. Liberdade de exercício profissional}

O art. 18 da Lei n. 9.656/98 estabelece a vedação do regime de exclusividade contratual entre o profissional ou a empresa prestadora de serviços e a administradora ou seguradora. Entendemos que as cooperativas também devem submeter-se a tal regra, não podendo alegar a incidência do regime da Lei n. 5.764/71, considerando os médicos como sócios cooperados, já que tal lei prevê a existência de duas espécies de cooperativas apenas: as de crédito e as habitacionais. A Lei n. 5.764 serve apenas de modelo de organização social às cooperativas médicas, cabendo, quanto aos aspectos relativos à prestação de serviços médicos, a plena observância da Lei n. 9.656. (26)

\section{IV.6. Necessário ressarcimento ao SUS}

$\mathrm{O}$ art. 32 da Lei n. 9.656/98 estabelece que as operadoras de planos de assistência à saúde deverão ressarcir os serviços de atendimento à saúde abrangidos nos contratos que forem prestados a seus consumidores ou dependentes em instituições públicas ou privadas, conveniadas ou contratadas, integrantes do Sistema Único de Saúde - SUS. A fundamentação desta regra é a de que toda assistência médico-hospitalar do consumidor de um plano ou seguro de saúde deve ter os seus custos arcados pelo respectivo operador, nos termos do contrato. Assim, se esse consumidor é atendido pelo SUS, o custo deve ser ressarcido por quem tem a obrigação de com ele arcar.

E não alega-se que os princípios da universalidade e da gratuidade, que regem o SUS, obrigam-no ao atendimento, independentemente de eventual vínculo contratual entre a pessoa atendida e um plano ou seguro de saúde.

Não podemos perder de vista que a operação de planos de saúde é uma atividade econômica organizada, que visa a obtenção de lucros. Haveria enriquecimento sem causa se a operadora não reembolsasse o Estado pela prestação de um serviço, cujo custo fosse, contratualmente, obrigada a arcar. Tal enriquecimento sem causa é ainda mais pernicioso se operado em detrimento do SUS, cuja fonte de custeio advém da arrecadação tributá-

(26) No mesmo sentido, Pasqualoto, 1999, p. 60. 
ria, sendo, assim, encargo de toda a população brasileira. Assim, mantendo obrigação contratualmente estabelecida a outrem, nada mais justo do que 0 Estado ressarcir-se das despesas.

\section{BIBLIOGRAFIA}

CANOTILHO J. J. Gomes; MOREIRA, Vital. "Fundamentos da Constituição". Coimbra: Coimbra, 1991.

EWALD, François. “L'Etat providence”. Paris: B. Grasset, 1986.

FRIEDMAN, Lawrence. "The Republic of choice-Law, Authority and Culture". Boston: Harvard University Press, 1994.

GRAU, Eros Roberto. "A ordem econômica na Constituição de 1988", 4ª ed., São Paulo: Malheiros, 1998.

GRINOVER, Ada Pelegrini et al. "Código Brasileiro de Defesa do Consumidor Comentado pelos autores do anteprojeto", $5^{\mathbf{a}}$ ed., Rio de Janeiro: Forense Universitária, 1998.

HALL, Mark A. \& ELLMAN, Ira M. "Health Care law and ethics". St. Paul (Minn): West Publ. Co., 1990.

LOPES, José Reinaldo de Lima. "Consumidores de seguros e planos de saúde: ou, doente também tem direitos". In MARQUES, Cláudia Lima, LOPES, José Reinaldo Lima e PFEIFFER, Roberto Augusto Castellanos. Saúde e Responsabilidade: seguros e planos de assistência privada à saúde, São Paulo: Revista dos Tribunais, 1999.

LUHMANN, Niklas. "El concepto de riesgo". In Las Consecuencias perversas de la modernidad. Josetxo Beriani (org.). Barcelona: Antropo, 1996.

MARQUES, Cláudia Lima. "Conflitos de leis no tempo e direito adquirido dos consumidores de planos e seguros de saúde". In MARQUES, Cláudia Lima, LOPES, José Reinaldo Lima e PFEIFFER, Roberto Augusto Castellanos. Saúde e Responsabilidade: seguros e planos de assistência privada à saúde, São Paulo: Revista dos Tribunais, 1999.

MARQUES, Cláudia Lima. "Contratos no Código de Defesa do Consumidor", $2^{\mathbf{a}}$ ed., São Paulo: Revista dos Tribunais, 1994.

MIRANDA, José Francisco Cavalcanti Pontes de. "Tratado de Direito Privado", Rio de Janeiro: Forense, 1974, tomo XLV.

NERY JÚNIOR, Nelson. "Código Brasileiro de Defesa do Consumidor", 5a ed., Rio de Janeiro: Forense Universitária, 1998. 
PASQUALOTO, Adalberto. "A regulamentação dos planos de seguros de assistência à saúde: uma interpretação construtiva". In MARQUES, Cláudia Lima, LOPES, José Reinaldo Lima e PFEIFFER, Roberto Augusto Castellanos. Saúde e Responsabilidade: seguros e planos de assistência privada à saúde. São Paulo: Revista dos Tribunais, 1999.

PFEIFFER, Roberto Augusto Castellanos. "Cláusulas relativas à cobertura de doenças, tratamentos de urgência e emergência e carências". In MARQUES, Cláudia Lima, LOPES, José Reinaldo Lima e PFEIFFER, Roberto Augusto Castellanos. Saúde e Responsabilidade: seguros e planos de assistência privada à saúde. São Paulo: Revista dos Tribunais, 1999.

SANTOS, J. M. Carvalho. "Código Civil Interpretado", 3ª ed., São Paulo: Saraiva, 1984, vol. 19.

SARRUBO, Mariângela. "A saúde na Constituição Federal e o contexto para a recepção da Lei n. 9.656/98". In MARQUES, Cláudia Lima, LOPES, José Reinaldo Lima e PFEIFFER, Roberto Augusto Castellanos. Saúde e Responsabilidade: seguros e planos de assistência privada à saúde. São Paulo: Revista dos Tribunais, 1999.

SILVA, José Luis Toro da. "Comentários à Lei de Planos de Saúde". Porto Alegre: Síntese, 1998. 